\title{
Lanthanide(III) Hexanuclear Circular Helicates: Slow Magnetic Relaxation, Toroidal Arrangement of Magnetic Moments, and Magnetocaloric Effects
}

\author{
Jingjing Lu, ${ }^{\dagger},{ }^{\dagger}$ Vincent Montigaud,${ }^{\S}$ Olivier Cador,${ }^{\S}$ Jianfeng $\mathrm{Wu},{ }^{\dagger}$ Lang Zhao, ${ }^{\dagger}$ Xiao-Lei Li,${ }^{\dagger}$ Mei \\ Guo, ${ }^{\dagger}$ Boris Le Guennic, ${ }^{*}, \S$ and Jinkui Tang ${ }^{*}, \dagger,+$
}

'State Key Laboratory of Rare Earth Resource Utilization, Changchun Institute of Applied Chemistry, Chinese Academy of Sciences, Changchun 130022, P. R. China

"School of Applied Chemistry and Engineering, University of Science and Technology of China, Hefei 230026, P. R. China ${ }^{\S}$ Univ Rennes, CNRS, ISCR (Institut des Sciences Chimiques de Rennes) - UMR 6226, F-35000 Rennes, France

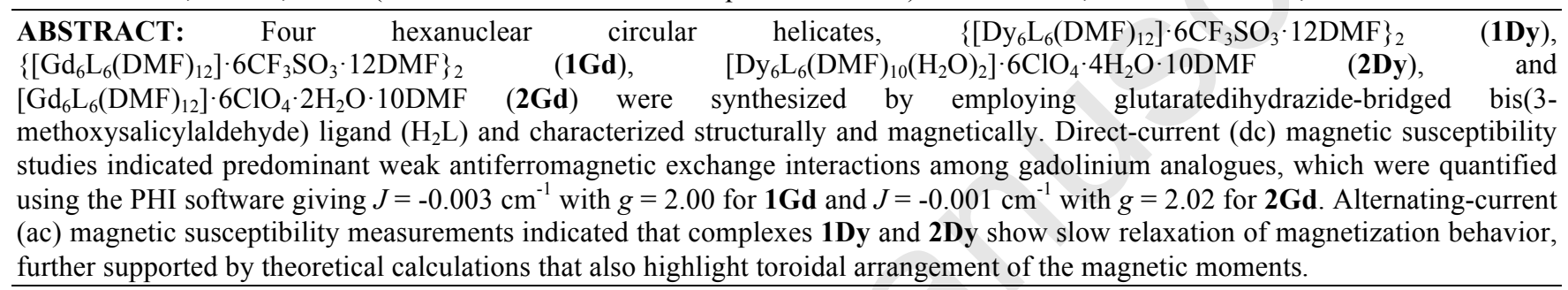

\section{INTRODUCTION}

The self-assembly of sophisticated molecular architectures, such as rotaxanes, ${ }^{1}$ catenanes, ${ }^{2}$ knots, ${ }^{3}$ links, ${ }^{4}$ polygons, ${ }^{5}$ polyhedras, ${ }^{6}$ helicates $^{7}$, and grids $^{8}$ is one of the huge achievements in the field of metallosupramolecular chemistry. In particular, molecular helicates have received considerable attention these years in light of their aesthetically fascinating structures, which have shown promising applications in chiral catalysis, enantioselective processes, molecular magnetism and supramolecular devices. ${ }^{9}$ Nevertheless, lanthanide-based polynuclear helicates have not been as developed as transition metal systems because of the difficulty in controlling the coordination environment of lanthanide ions exhibiting high and versatile coordination numbers, kinetic lability, as well as weak stereochemical preferences. $^{10}$ Despite these unprecedented difficulties, a series of lanthanide helicates with different topologies dominated by single- ${ }^{11}$ double-,${ }^{11 \mathrm{~b},}{ }^{12}$ triple-, ${ }^{10 a}, 13$ and quadruple- ${ }^{10 \mathrm{~d}, 14}$ stranded helicates have been prepared and structurally characterized. However, circular analogues have been rarely obtained and less investigated. ${ }^{10 c}$, ${ }_{10 f,} 15$ In particular, the $4 f$-only polynuclear circular helicates remain relatively scarce.

On the other hand, lanthanide-based coordination clusters are of particular interest. Indeed, they often display some intriguing magnetic behaviors, such as single-molecule magnets (SMMs), ${ }^{16}$ single-molecule toroics (SMTs) ${ }^{17}$ and magnetocaloric effects (MCEs). ${ }^{18}$ Generally speaking, molecules featuring Ising-like magnetic anisotropy and vortex distributions of magnetic dipoles are anticipated to show not only SMMs but also SMTs behaviors. ${ }^{17 c, 19}$ For instance, the anisotropic $\mathrm{Dy}^{\mathrm{III}}, \mathrm{Tb}^{\mathrm{III}}, \mathrm{Ho}^{\mathrm{III}}$, and $\mathrm{Er}^{\mathrm{III}}$ ions were proposed to construct SMMs with higher effective energy barrier, ${ }^{20}$ while a "vortex-like" spatial distribution of local magnetic moments may result in toroidal moments characteristic of SMT behavior. ${ }^{17 \mathrm{~d}}$ Moreover, a large-spin ground state with inappreciable magnetic anisotropy, a large magnetic density, and dominant ferromagnetic exchange interactions are indispensable for those molecules with magnificent MCEs. ${ }^{21}$ Thus the isotropic $\mathrm{Gd}^{\mathrm{III}}$ ions with $S=7 / 2$ are the main candidates in the construction of polynuclear clusters with significant MCEs. ${ }^{22}$ Following this, some remarkable results in lanthanide-based polynuclear systems have been achieved: a number of complexes including $\mathrm{Dy}_{2},{ }^{23} \mathrm{Dy}_{5},{ }^{24} \mathrm{Dy}_{4} \mathrm{~K}_{2}{ }^{25}$ and $\mathrm{Ho}_{5}{ }^{24}$ which exhibit some of the largest anisotropy barriers have been described in the literature. Especially $\mathrm{Dy}_{4} \mathrm{~K}_{2}{ }^{25}$ displays the highest energy barrier of $842 \mathrm{~K}$ in polynuclear SMMs. The enhanced toroidal moments and SMMs behavior were realized in the coupled $\mathrm{Dy}_{3}$ triangles, ${ }^{17 \mathrm{~b}}$ and a toroidal magnetic moment has been identified in a non-planar $\mathrm{Dy}_{4}$ cubane complex. ${ }^{26}$ The $\left[\mathrm{Ln}_{60}\right]$ nanocages have the largest MCE with $-\Delta S_{\mathrm{m}}=66.5 \mathrm{~J} \mathrm{~kg}^{-1} \mathrm{~K}^{-1} \cdot{ }^{27}$ In addition, it has been proposed that high symmetry together with strong intramolecular interaction between different centers in metallocycle can possibly give rise to non-magnetic ground state with a net toroidal magnetic moment. ${ }^{19 c,} 28$ Thus lanthanide-based circular helicates with high symmetry seem to hold great promise in acquiring SMMs with a toroidal moment arrangement in the ground state.

As part of our research interests, we have long been focusing on using Schiff-base ligands to create larger pure $4 f$ polynuclear clusters with fantastic magnetic properties. ${ }^{10 \mathrm{~b}, 29}$ Herein, we successfully synthesized four novel lanthanidebased hexanuclear circular helicates, namely, $\left\{\left[\mathrm{Dy}_{6} \mathrm{~L}_{6}(\mathrm{DMF})_{12}\right] \cdot 6 \mathrm{CF}_{3} \mathrm{SO}_{3} \cdot 12 \mathrm{DMF}\right\}_{2} \quad$ (1Dy), $\left\{\left[\mathrm{Gd}_{6} \mathrm{~L}_{6}(\mathrm{DMF})_{12}\right] \cdot 6 \mathrm{CF}_{3} \mathrm{SO}_{3} \cdot 12 \mathrm{DMF}\right\}_{2}$ $\left[\mathrm{Dy}_{6} \mathrm{~L}_{6}(\mathrm{DMF})_{10}\left(\mathrm{H}_{2} \mathrm{O}\right)_{2}\right] \cdot 6 \mathrm{ClO}_{4} \cdot 4 \mathrm{H}_{2} \mathrm{O} \cdot 10 \mathrm{DMF} \quad$ (2Dy) and $\left[\mathrm{Gd}_{6} \mathrm{~L}_{6}(\mathrm{DMF})_{12}\right] \cdot 6 \mathrm{ClO}_{4} \cdot 2 \mathrm{H}_{2} \mathrm{O} \cdot 10 \mathrm{DMF} \quad(\mathbf{2 G d})$, using the 
elaborately chosen multitopic ligand glutaratedihydrazidebridged bis(3-methoxysalicylaldehyde) $\left(\mathrm{H}_{2} \mathrm{~L}\right.$, Scheme $\left.\mathrm{S} 1\right)$. Their crystal structures were determined by single-crystal Xray diffraction. Magnetic studies revealed that the gadolinium analogues 1Gd and 2Gd exhibiting significant MCEs are best suitable for the design of cryogenic refrigeration materials, while the dysprosium derivatives 1Dy and 2Dy show singlemolecule-magnet-like (SMM-like) behavior with rare toroidal magnetic moments.

\section{RESULTS AND DISCUSSION}

Synthetic Aspects. It has been shown that the combination of hydrazone-based ligands with great flexibility and $\mathrm{Ln}^{\text {III }}$ ions can result in the formation of higher homologues of helicates. ${ }^{10 \mathrm{f}, 14 \mathrm{a}, 10 \mathrm{~d}}$ In the present work, the reactions of ligand $\mathrm{H}_{2} \mathrm{~L}$ and the corresponding lanthanide salts in N,Ndimethylformamide (DMF), under basic conditions, produce yellow crystals of $1 \mathbf{L n}$ and $2 \mathbf{L n}(\mathbf{L n}=\mathbf{D y}, \mathbf{G d})$ suitable for single crystal X-ray diffraction in good yield after slow diffusion of diethyl ether at room temperature (detailed information in the Supporting Information). Crystallographic data and structure refinement details are summarized in Table S1, while some important bond parameters are given in Tables S2-S6. The phase purity of the bulk samples were checked by powder X-ray diffraction analysis of these compounds (Figure S1).

Structure. Single crystal X-ray diffraction analysis (Figures $1-2$, S2-S14) revealed that complexes $\mathbf{1 D y}$ and $\mathbf{1 G d}$ crystallize in the trigonal space group $R \overline{3}$ with $\mathrm{Z}=3$, while complexes 2Dy and 2Gd belong to the triclinic space group $P \overline{1}$ with $Z=1$. Although their asymmetric units are different, all the complexes possess similar structural topology with a wheelshaped hexametallic core. Therefore, only the structure of complex 1Dy will be described here in detail as representative.

As depicted in Figure 1, complex 1Dy is composed of a hexanuclear $\mathrm{Dy}_{6}$ core, which is wrapped orderly by six intercrossing ligand strands along a genuine 6-fold axis defined by the six Dy ${ }^{\text {III }}$ ions, giving rise to a hexanuclear circular helicate architecture. The remaining coordination sites of Dy ${ }^{\text {III }}$ ions are fulfilled by DMF molecules. The redundant positive charges are further balanced by $\mathrm{CF}_{3} \mathrm{SO}_{3}{ }^{-}$ counteranions in the lattice. The unit cell of 1Dy is comprised of two slightly different molecules, identified as $\mathbf{1 D y} \mathbf{A}^{\mathbf{A}}$ and 1Dy $^{\text {B }}$ (Figure S2). In the asymmetric unit, each of the Dy ${ }^{\text {III }}$ ions is in the same $\mathrm{N}_{2} \mathrm{O}_{6}$ coordination environment constituted by two deprotonated $\mathrm{L}$ ligands with two tridentate coordination pockets (ONO), and two DMF molecules providing two $\mathrm{O}$ donor atoms. Accordingly, both the Dy ${ }^{\text {III }}$ centers are eight-coordinated but with different coordination polyhedra: DyA lies in a slightly distorted triangular dodecahedron $\left(D_{2 \mathrm{~d}}\right)$ coordination environment, whereas DyB has a distorted biaugmented trigonal prism $\left(C_{2 \mathrm{v}}\right)$ geometry, with CshMs (the Continuous Shape Measures values) of 1.766, 2.019 for DyA and DyB, respectively (Table S4) ${ }^{30}$ The Dy-O bond lengths are in the ranges of 2.188(6)-2.404(6) (for $\mathrm{O}$ atoms from the $\mathrm{H}_{2} \mathrm{~L}$ ligands) and 2.316(6)-2.421(7) $\AA$ (for O atoms from the coordinated DMF molecules); while the average Dy-N distance is 2.539(7) $\AA$.

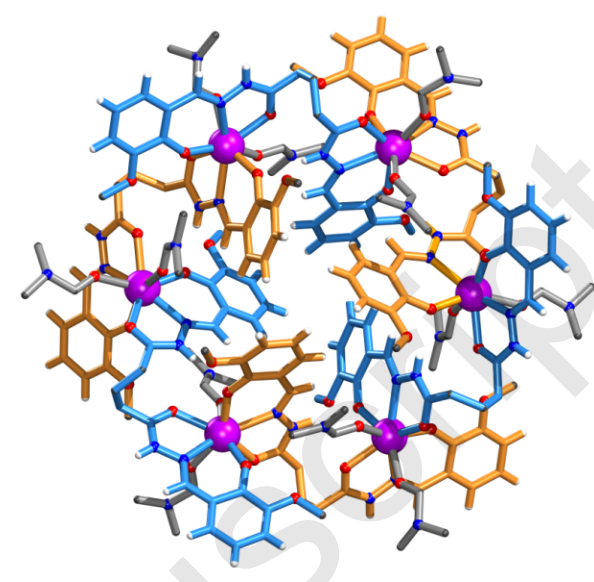

Figure 1. Molecular structure of 1Dy with selected hydrogen atoms, external counteranions, and solvent molecules omitted for clarity (Dy violet, $\mathrm{N}$ blue, $\mathrm{O}$ red and $\mathrm{H}$ white with ligands adopt two different colors).

Interestingly, both $\mathrm{Dy}_{6}$ hexagons within the 1Dy complex are close to the equilateral hexagon and the nearest neighbor Dy $\cdots$ Dy distances within the hexagons are 7.282(1) and 7.272(1) $\AA$ for DyA and DyB, respectively. The $\angle$ Dy-Dy-Dy angles of adjacent three Dy centers within the hexagons approach $120^{\circ}$ (Table S7). The arrangement of the six Dy atoms is nearly coplanar: the average deviations of these atoms from the best-fit mean planes through the $\mathrm{Dy}_{6}$ cores are $0.2445(1), 0.2724(1) \AA$ for DyA and DyB, respectively.

It is worth mentioning that the cationic core structures of 2Dy and 2Gd are almost identical, except that two coordinated $\mathrm{H}_{2} \mathrm{O}$ molecules in 2Dy replace two coordinated DMF molecules in $\mathbf{2 G d}$, as observed from their formulas (Figures S5 and S7). Moreover, 1Gd shows a core structure similar to those of 1Dy and 2Gd (Figure S6). For complexes 1Dy, 1Gd, 2Dy and 2Gd, the shortest intermolecular Ln $\cdots$ Ln distances are $9.631,9.687,10.310$, and $10.972 \AA$, respectively, which may suggest relatively weak intermolecular magnetic interactions (Tables S7 and S8).

Table 1. Different dihedral angles observed in each ligand strand in complexes 1Dy and 2Dy.

\begin{tabular}{ccccc}
\hline Complex & Ligand & $\begin{array}{c}\text { Dihedral angle } \\
\text { between two meridional planes }\left[{ }^{\circ}\right]\end{array}$ & $\begin{array}{c}\text { Dihedral angle } \\
{\left[-(\mathrm{O}) \mathrm{C}-\mathrm{CH}_{2}-\mathrm{CH}_{2}-\mathrm{CH}_{2}-\mathrm{C}(\mathrm{O})-\right]\left[{ }^{\circ}\right]}\end{array}$ & $\begin{array}{c}\text { Angle between two } \\
{[-(\mathrm{O}) \mathrm{C}-\mathrm{NH}-] \text { functions }\left[{ }^{\circ}\right]}\end{array}$ \\
\hline \multirow{2}{*}{ 1Dy } & Strand 1 & 10.74 & 65.12 & 4.21 \\
& Strand 2 & 11.61 & 69.46 & 6.55 \\
\hline \multirow{2}{*}{ 2Dy } & Strand 1 & 7.13 & 64.11 & 4.52 \\
& Strand 2 & 4.92 & 62.79 & 7.82 \\
& Strand 3 & 3.36 & 63.60 & 5.12 \\
\hline
\end{tabular}



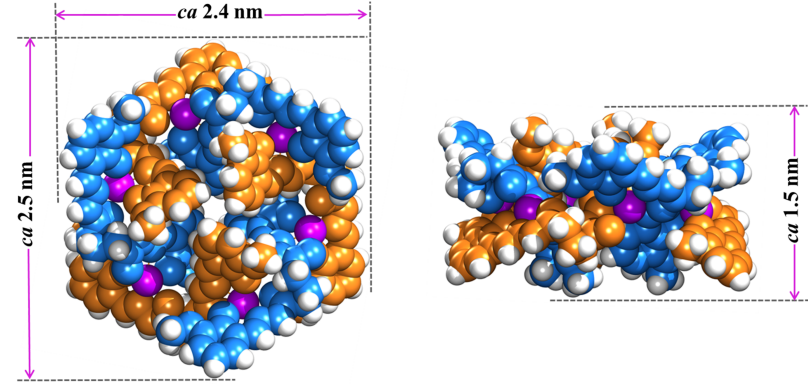

Figure 2. Space-filling models of top view (left) and side view (right), with the ligands colored differently to highlight the circular helicity. Coordinated DMF molecules, external counteranions, and solvent molecules are omitted for clarity.

Overall, the six Dy atoms lie at the six vertices of a slightly twisted equilateral hexagon, whose edges are bridged by six deprotonated ligands with 'over and under' conformation in a helical fashion, producing a hexanuclear single-stranded circular helicate structure. Furthermore, the complete $\left[\mathrm{Dy}_{6} \mathrm{~L}_{6}(\mathrm{DMF})_{12}\right]^{6+}$ core has a rare $S_{6}$ symmetry thanks to the crystallographic centrosymmetry, demonstrated by the spacefilling representation of core structure illustrated in Figure 2, which exhibits the nanometer-scale dimensions $(2.4 \mathrm{~nm} \times 2.5$ $\mathrm{nm} \times 1.5 \mathrm{~nm}$ ) and a size-negligible central hole. Besides, the present complexes join only a handful of existing $4 f$-only hexanuclear circular helicates. ${ }^{10 \mathrm{f}}$

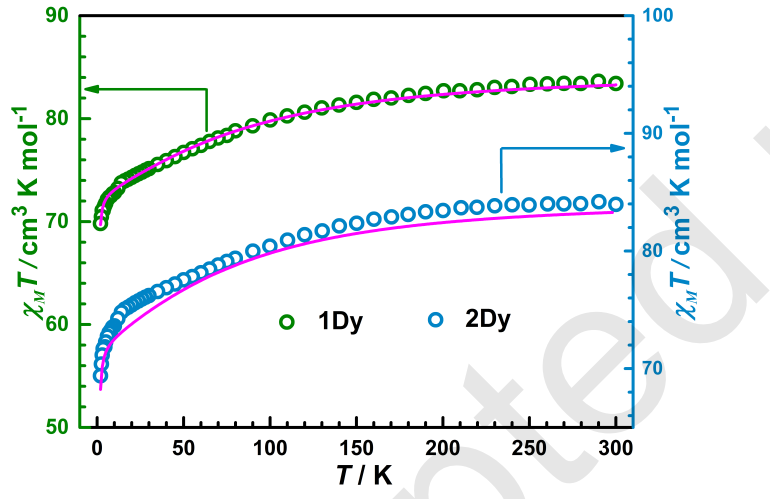

Figure 3. The measured (empty circles) and calculated (purple lines) magnetic susceptibility for 1Dy and 2Dy.

The generation of this hexanuclear circular structure is the result of several key factors. First, the two tridentate coordination pockets are well-separated by a flexible alkyl linker, which is supposed to offer variable coordination modes, further leading to the self-assembly of interesting clusters or extended networks. $^{7 \mathrm{a}, 7 \mathrm{c}, 31}$ For complexes 1Dy and 2Dy, each of the ligand strand presents a pseudo "C-shape" framework owing to flexible $-\mathrm{CH}_{2}-\mathrm{CH}_{2}-\mathrm{CH}_{2}-$ moieties. The torsional angles between two $-(\mathrm{O}) \mathrm{C}-\mathrm{CH}_{2}-\mathrm{CH}_{2}-\mathrm{CH}_{2}-\mathrm{C}(\mathrm{O})$ - units in each ligand strand are in the range of $62.79-69.46^{\circ}$. It is worth mentioning that the angles of the two $-\mathrm{C}(\mathrm{O})-\mathrm{NH}$ - functions within one ligand strand are $4.21-7.82^{\circ}$, which are smaller than the values previously reported for tetranuclear and dinuclear helicates $^{14 a}$, 32 (Table 1). This arrangement is further supplemented by significant intramolecular H-bonding interactions between hydrazide- $\mathrm{H}$ atoms $(=\mathrm{N}-\mathrm{NH}-\mathrm{C}(\mathrm{O})-)$ and the methoxy oxygens as well as the phenolate oxygens of the adjacent $\mathrm{L}^{2-}$ ligands (Figures S4-S5). Apart from the above intramolecular interactions, extensive weak interactions such as $\mathrm{C}-\mathrm{H} \cdots \mathrm{O}, \pi \cdots \pi$ and $\mathrm{C}-\mathrm{H} \cdots \pi$ interactions were also detected in the crystal structure (Figures S8 and S9). Finally, the resulting small cavity is empty probably due to steric hindrance. Thus, we definitively rule out the possible existence of anions template effects. In addition, it is important to highlight that each ligand can capture simultaneously two neighboring $\mathrm{Dy}{ }^{\mathrm{III}}$ ions into its two tridentate coordination pockets (ONO) at both ends of the flexible ligand. Therefore, it is conceivable that the formation of hexanuclear circular helicates was mainly owing to the flexibility of the ligand and the presence of the odd number of flexible $\left(-\mathrm{CH}_{2}-\mathrm{CH}_{2}-\mathrm{CH}_{2}-\right)$ spacers in it.

Magnetic properties. To investigate the magnetic behaviors of the circular helical $\mathrm{Ln}_{6}$ complexes, static directcurrent (dc) magnetic susceptibility measurements were conducted on polycrystalline samples ranging from 2 to $300 \mathrm{~K}$ and under an external field of 1000 Oe. As shown in Figure 3 and Figure S15, the room-temperature $\chi_{\mathrm{M}} T$ products of all complexes are well in agreement with the calculated value for six $\mathrm{Dy}^{\mathrm{III}}$ or $\mathrm{Gd}^{\mathrm{III}}$ ions, respectively, indicating the free-ion approximation applies. ${ }^{33}$ Upon cooling, the $\chi_{\mathrm{M}} T$ values of 1Dy and 2Dy show a slight decline until $50 \mathrm{~K}$, and then faster decreases occur reaching the minimal values of 69.81 and $70.64 \mathrm{~cm}^{3} \cdot \mathrm{K} \cdot \mathrm{mol}^{-1}$ at $2.0 \mathrm{~K}$, respectively, which can be ascribed to the combined effects from the progressive depopulation of excited Stark sublevels in anisotropic Dy ${ }^{\text {III }}$ ions and also possible weak intra/intermolecular interactions between the Dy ${ }^{\mathrm{III}}$ ions. ${ }^{17 \mathrm{e}, 34}$ In contrast, for $\mathbf{1 G d}$ and $\mathbf{2 G d}, \chi_{\mathrm{M}} T$ values do not exhibit a clear decline, but remain nearly constant down to $20 \mathrm{~K}$, which is expected for such an isotropic ion; and then decrease slowly to the minimum values of 46.20 and $47.05 \mathrm{~cm}^{3} \cdot \mathrm{K} \cdot \mathrm{mol}^{-1}$ at $2.0 \mathrm{~K}$, respectively. This drop might be ascribed to very weak magnetic interactions between the $\mathrm{Gd}^{\mathrm{III}}$ ions.
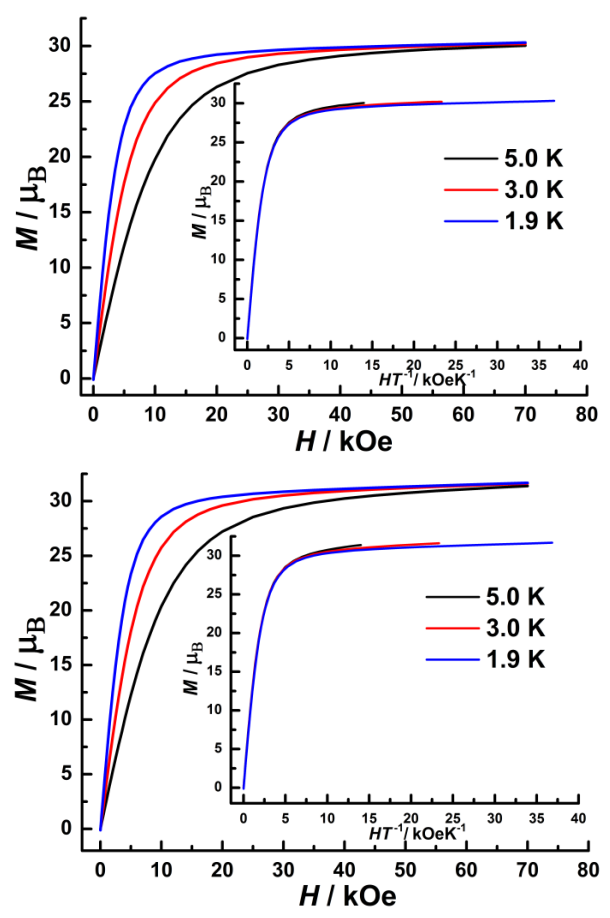
Figure 4. Field dependences of magnetization in the field between 0 to $70 \mathrm{kOe}$ and at the temperatures of 1.9, 3.0 and $5.0 \mathrm{~K}$. Insets: Plots of the reduced magnetization $M$ vs. $H T^{-1}$. 1Dy (top); 2Dy (bottom).

Due to the absence of orbital angular momentum contribution to the magnetic moment within the gadolinium complexes, the strength of the magnetic coupling in $\mathbf{1 G d}$ and 2Gd can be estimated quantitatively. To avoid overparameterization, only one exchange $J$ value was taken into account. Thus the magnetic susceptibility data of the two complexes can be fitted following the Hamiltonian: $\widehat{H}=-2 J \hat{S}_{G d} \cdot \hat{S}_{G d}$, by using the PHI package. ${ }^{35}$ The best fit affords parameters $J=-0.003 \mathrm{~cm}^{-1}$ with $g=2.00$ for $\mathbf{1 G d}$, and $J=-0.001 \mathrm{~cm}^{1}$ with $g=2.02$ for $\mathbf{2 G d}$, respectively (Figure S15). The significantly small and negative $J$ substantiates very weak antiferromagnetic interactions, probably owing to the large intramolecular distance between the $\mathrm{Gd}^{\mathrm{III}}$ centers. The $\chi_{\mathrm{M}}{ }^{1}$ vs. $T$ plots fitted with Curie-Weiss law between 2 to 300 $\mathrm{K}$ further verify the presence of antiferromagnetic interactions (Figure S16).
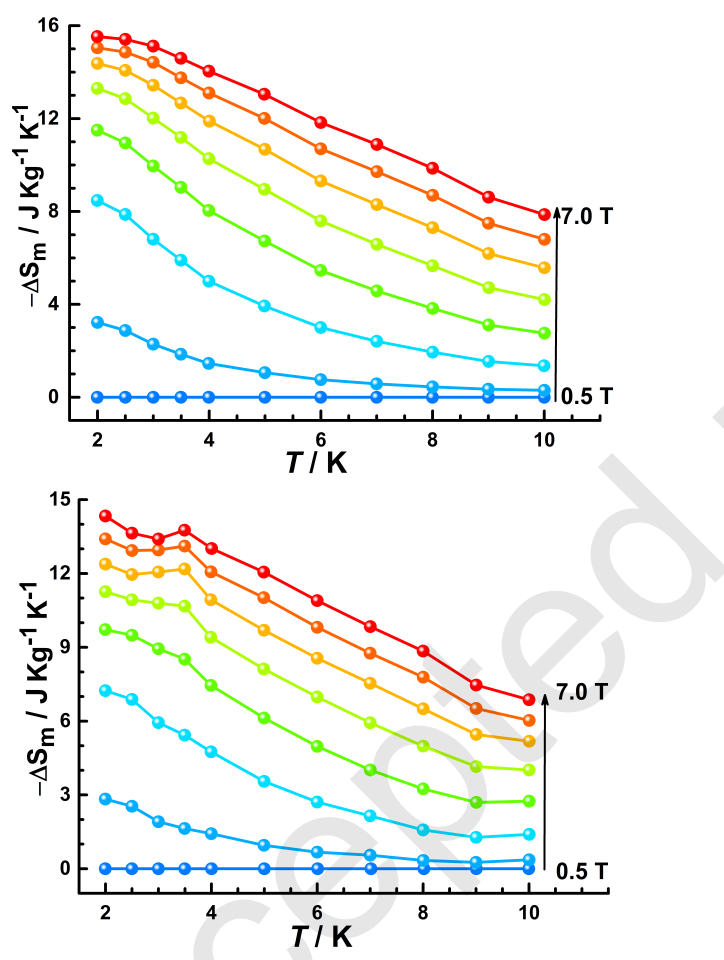

Figure 5. Temperature dependences of the magnetic entropy change $\left(-\Delta S_{\mathrm{m}}\right)$ at indicated fields $(0.5-7.0 \mathrm{~T})$ for $\mathbf{1 G d}$ (top) and 2 Gd (bottom).

The field dependence of the magnetization $(M)$ measurements were performed below $5.0 \mathrm{~K}$ in the field range of 0-70 kOe (Figure 4 and Figure S17). For 1Dy and 2Dy, the magnetizations display rapid rises at low-field regime before slight increases at high-field regime, and the corresponding maximum values reached are $30.31,31.67 \mu_{\mathrm{B}}$ at $2.0 \mathrm{~K}$ and 70 $\mathrm{kOe}$, which are less than the predicted saturation value for six isolated Dy ${ }^{\text {III }}$ ions $\left(10 \mu_{\mathrm{B}}\right.$ per Dy $\left.{ }^{\text {III }}\right){ }^{17 \mathrm{a}}$ This is most likely due to the large magnetic anisotropy or crystal-field effects at the Dy ${ }^{\text {III }}$ ions eliminating the 16 -fold degeneracy of the ${ }^{6} \mathrm{H}_{15 / 2}$ ground state. ${ }^{5 \mathrm{a}, 36}$ However, these values are much closer to the expected value for six non-interacting Dy ${ }^{\mathrm{III}}$ ions $\left(5.2 \mu_{\mathrm{B}}\right.$ per $\mathrm{Dy}^{\mathrm{III}}$ ) considering considerable ligand-field effects. ${ }^{17 \mathrm{a},}{ }^{37}$ Furthermore, the lack of superposition of $M$ vs. $H / T$ curves (Figure 4 inset) on a single master curve implies the presence of non-negligible magnetic anisotropy and/or low-lying excited states. ${ }^{38}$ Whereas the magnetizations of $\mathbf{1 G d}$ and $\mathbf{2 G d}$ show smooth increase in the whole field range, eventually approaching the saturation value of $42 \mu_{\mathrm{B}}$.

Generally, the large magnetization values may facilitate large magnetocaloric effects (MCEs). Thus we evaluate the MCEs of $\mathbf{1 G d}$ and $\mathbf{2 G d}$ according to the Maxwell relationship $\Delta S_{\mathrm{m}}(T)=\int[\partial M(T, H) / \partial T]_{\mathrm{H}} \mathrm{d} H \quad{ }^{39}$ The magnetic entropy change $\left(\Delta S_{\mathrm{m}}\right)$ at different fields and temperatures could be calculated from the experimentally obtained $M(H, T)$ data (Figure S17). As can be seen from Figure 5, with decreasing the temperatures from 10 to $2 \mathrm{~K}$, the resulting $-\Delta S_{\mathrm{m}}$ values of 1Gd and 2Gd gradually increase and the maximum entropy changes obtained at $2 \mathrm{~K}$ and $7 \mathrm{~T}$ are 14.34 and $15.53 \mathrm{~J} \mathrm{~kg}^{-1}$ $\mathrm{K}^{-1}$, respectively. However the calculated $-\Delta \mathrm{S}_{\mathrm{m}}$ values following the equation $-\Delta S_{\mathrm{m}}=n R \ln (2 S+1)\left(S=7 / 2\right.$ for $\mathrm{Gd}^{\mathrm{III}}$

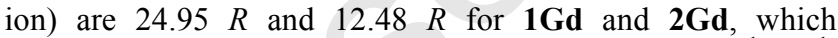
correspond to the values 18.88 and $17.66 \mathrm{~J} \mathrm{~kg}^{-1} \mathrm{~K}^{-1}$, respectively. The experimental values for the two complexes are slightly lower than the theoretical values, possibly due to the use of large $\mathrm{H}_{2} \mathrm{~L}$ ligand together with dominant antiferromagnetic interactions in these complexes. ${ }^{14 a, 34,40}$
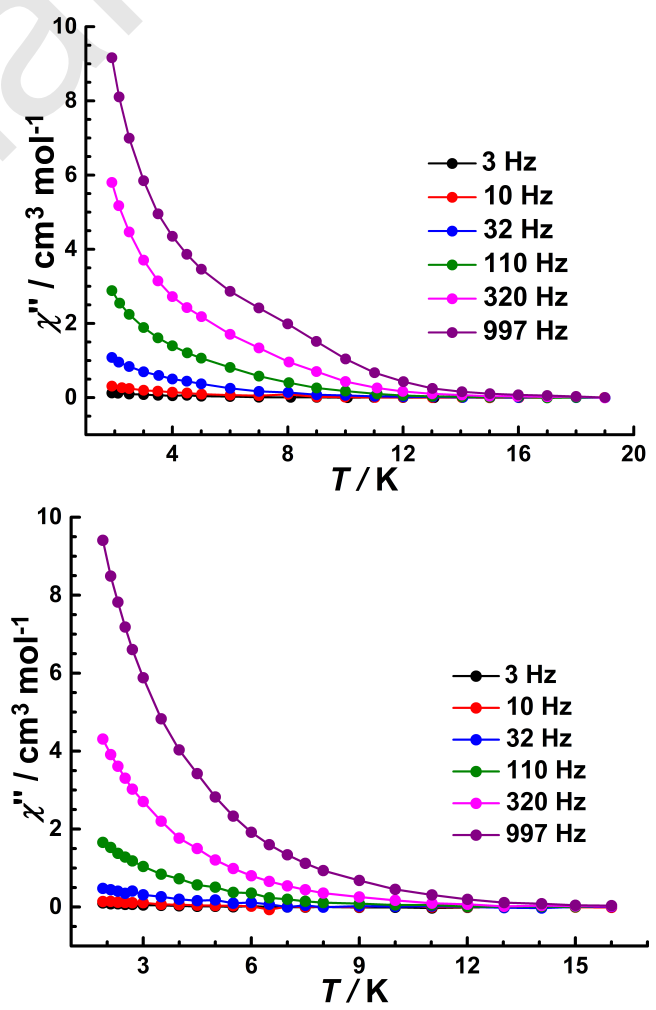

Figure 6. Temperature-dependent out-of-phase ( $\chi$ ") signals for 1Dy (top) and 2Dy (bottom) at indicated frequencies, under zero dc field.

Alternating current (ac) magnetic susceptibility experiments of complexes 1Dy and 2Dy were undertaken at 3.0 Oe ac field with a zero de field in order to investigate the spin dynamics. 
Remarkably, complexes 1Dy and 2Dy exhibit pronounced frequency-dependent out-of-phase ( $\chi$ ”) signals below 15 and $13 \mathrm{~K}$, respectively, indicating slow magnetic relaxation with characteristic of SMM behavior (Figure 6). However, no clear signature of maxima could be observed within the apparatus window even at frequencies as high as $997 \mathrm{~Hz}$, suggesting a small anisotropy energy barrier and/or the occurrence of fast quantum tunneling of magnetization (QTM). Thus, we roughly evaluate the energy barrier and relaxation time with the Debye model based on equation (1). ${ }^{41}$

$\ln \left(\chi^{\prime \prime} / \chi^{\prime}\right)=\ln \left(\omega \tau_{0}\right)+U_{\text {eff }} / T$

The best fitting gives an energy barrier of $\sim 0.46$ and $\sim 0.79 \mathrm{~K}$ with the pre-exponential factors $\tau_{0}$ of $1.40 \times 10^{-4}$ and $2.65 \times$ $10^{-4} \mathrm{~s}$ for 1Dy and 2Dy, respectively (Figure S19). As mentioned above, DyA and DyB centers of 1Dy are located in the distorted triangular dodecahedron and biaugmented trigonal prism coordination geometries, respectively; while for 2Dy, all Dy ${ }^{\text {III }}$ centers comprise triangular dodecahedron geometry. Therefore, the obtained small barriers for 1Dy and 2Dy are mainly explained by the low and distorted coordination geometries, which may disfavor the axial anisotropy of the Dy ${ }^{\text {III }}$ ions resulting in fast QTM relaxation.

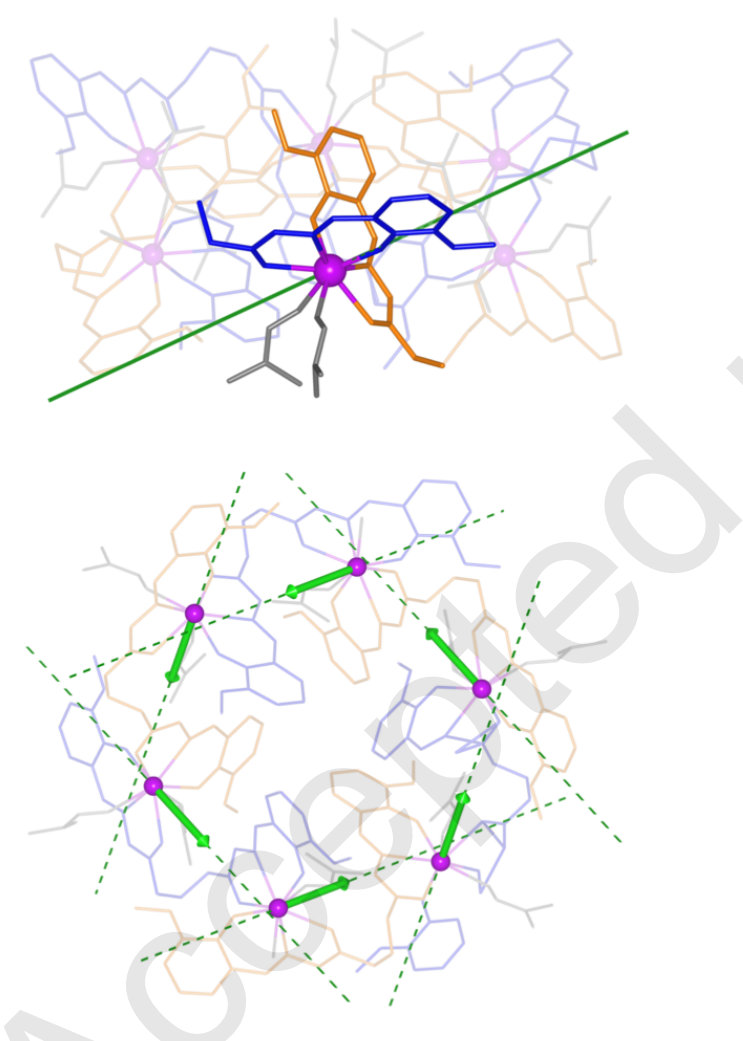

Figure 7. Representation of the ground state $g_{Z}$ component of the $g$-tensor for an isolated Dy ${ }^{\text {III }}$ ion (green line top) and projection of the magnetic axis on each of the magnetic center of the hexanuclear structure of 2Dy (bottom).

Theoretical calculations. To give more insights into the magnetic behavior of both 1Dy and 2Dy, ab-initio calculations were carried out using the SA-CAS(9,7)SCF/RASSI-SO method (details in the supporting information). Computations on the whole architecture being too expensive, a model containing a single Dy ${ }^{\text {III }}$ center by cutting the bridging glutaratedihydrazide ligands (Figure S21) is built for each asymmetric Dy ${ }^{\text {III }}$ center of both compounds. Such approach generated 2 models for 1Dy $\left(\left[\mathrm{DyA}(\mathrm{DMF})_{2}(\mathrm{~L})\right]^{+}\right.$and $\left[\mathrm{DyB}(\mathrm{DMF})_{2}(\mathrm{~L})\right]^{+}$, Figure $\left.\mathrm{S} 22\right)$ and 3 models for 2Dy $\left(\left[\mathrm{Dy} 1\left(\mathrm{H}_{2} \mathrm{O}\right)(\mathrm{DMF})(\mathrm{L})\right]^{+}, \quad\left[\mathrm{Dy} 2(\mathrm{DMF})_{2}(\mathrm{~L})\right]^{+} \quad\right.$ and $\left[\mathrm{Dy} 3(\mathrm{DMF})_{2}(\mathrm{~L})\right]^{+}$, Figure S23). In all models, the numbering of the Dy centers follows the one of the experimental section (Figures S2-S5). The resulting dc magnetic properties are then summed over the six magnetic centers for 2Dy $(2$ Dy $1+2$ Dy2 +2 Dy3). For 1Dy, the data are averaged over the two hexanuclear molecules $\left(\left\{\mathrm{DyA}_{6}\right\}\right.$ and $\left.\left\{\mathrm{DyB}_{6}\right\}\right)$ to represent the overall dc magnetic properties since both units exhibit similar magnetic behaviors (Figure S24). For both 1Dy and 2Dy, a good agreement with experimental data in the hightemperature range of the $\chi_{\mathrm{M}} T$ product and in the $M$ vs. $\mathrm{H}$ curves at $2 \mathrm{~K}$ is found (Figures S25 and S26, blue curves). Indeed, for both systems, each asymmetric Dy ${ }^{\text {III }}$ ion presents an almost pure $\mid \pm 15 / 2>$ ground state $\left(\geq 95 \% M_{J}= \pm 15 / 2\right)$ defined by a g-tensor with a major $g_{z}$ component above 19.5 denoting a strongly axial, Ising-type, magnetic anisotropy axis (Tables S9-S13). The various distorted $D_{2 \mathrm{~d}}$ coordination sphere geometries observed for DyA (1Dy) and all centers of 2Dy lead to modulations of the energy splitting of the ground state multiplet ${ }^{6} \mathrm{H}_{15 / 2}$ ranging from 487 (DyA, 1Dy) to $540 \mathrm{~cm}^{-1}$ (Dy3, 2Dy). While in the case of DyB, the $\mathrm{C}_{2 \mathrm{v}}$ symmetry of the coordination sphere leads to a ground state multiplet spanning over $570 \mathrm{~cm}^{-1}$. For both complexes, all Dy ${ }^{\text {III }}$ centers exhibit a ground state easy axis oriented along one of the oxygen atoms of the tridentate coordination pockets (ONO) from one of the L ligands (Figure 7, top) forming an angle of $50^{\circ}$ with the $S_{6}$ axis. The projection of the magnetic axis onto the six Dy ${ }^{\text {III }}$ ions shows a $g_{Z} \cdots g_{Z}$ angle of about $40^{\circ}$ between neighboring centers (Figure 7, bottom and Figures S27 and S28). The directions of the magnetic axis on each Dy ${ }^{\text {III }}$ ion recover the 6-fold symmetry, leading to a toroidal arrangement of the magnetic moments. Generally, the toroidal arrangement of magnetic moments is the result of wheel-shaped topology of the spin centers with specific magnetic interactions. Thus, the toroidal moments may be dictated by molecular symmetry, local magnetic moment, and magnetic interactions between metal centers. Besides, the toroidal magnetic moment has been viewed as the promising candidate for future applications in quantum computing and information storage in light of their insensitivity to homogeneous magnetic fields. ${ }^{17 a, 17 d}$

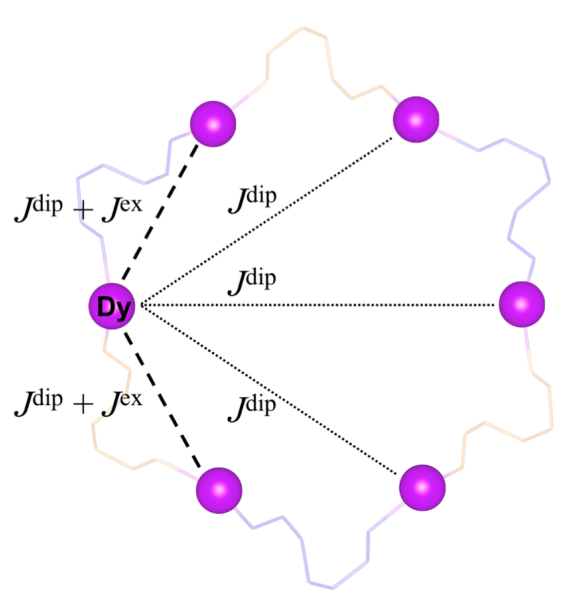

Figure 8. Schematic representation of the intramolecular magnetic interactions considered in the calculations for a given Dy ${ }^{\text {III }}$ ion. 
The computation of the transition elements of the magnetic moment for each Dy centers (Figures S29-S33) reveals similar mechanism between 1Dy and 2Dy involving a ThermallyAssisted QTM (TA-QTM) process through $1^{\text {st }}$ and $2^{\text {nd }}$ excited states leading to calculated barriers between 100 and $200 \mathrm{~cm}^{-1}$.

Due to the large intermolecular Dy $\cdots$ Dy distances observed in both compounds, only intramolecular interactions are considered in the calculations. These magnetic interactions occurring within a single $\left\{\mathrm{Dy}_{6}\right\}$ crown were simulated in the Lines model and each center was treated with an effective spin $\widetilde{S}=1 / 2$, as implemented in the POLY_ANISO software. The resulting exchange Hamiltonian is dressed following the interacting pairs depicted in Figure 8 and diagonalized in the basis of the local ground state doublet of each Dy ${ }^{\text {III }}$ center resulting in $2^{6}=64$ interaction states $(32$ Kramers Doublets, KDs). This procedure was also employed previously to treat similar architectures. ${ }^{19 \mathrm{c}}$

$$
\widehat{H_{e x}}=-\sum_{i}^{6} \sum_{j>i}^{6} J^{d i p} \widetilde{S}_{l} \tilde{S}_{j}-\sum_{i}^{6} J^{e x} \widetilde{S}_{l} \tilde{S}_{i+1}
$$

As one can read from equation (2) and Figure 8, we considered intramolecular dipolar coupling for all possible magnetic pairs within a $\left\{\mathrm{Dy}_{6}\right\}$ unit while exchange terms were considered only in the case of neighboring centers. When only considering intramolecular dipolar interactions, a strong decrease of the $\chi_{\mathrm{M}} T$ product at low temperature is observed with a value of $71.7 \mathrm{~cm}^{3} \cdot \mathrm{K} \cdot \mathrm{mol}^{-1}$ and $71.5 \mathrm{~cm}^{3} \cdot \mathrm{K} \cdot \mathrm{mol}^{-1}$ at $2 \mathrm{~K}$ for 1Dy and 2Dy, respectively (Figures S25 and S26, green curves). The resulting energy splitting of the $32 \mathrm{KDs}$ arising from the dipolar interactions was found to span over almost $1.5 \mathrm{~cm}^{-1}$ (Tables S14-S16). This value is much smaller than the those previously reported for the $\left\{\mathrm{Dy}_{6}\right\}$ molecular architectures $\left(4.4 \text { and } 4.8 \mathrm{~cm}^{-1}\right)^{17 \mathrm{f}, 19 \mathrm{c}, 37 \mathrm{~b}}$ assessing the weakness of the magnetic interactions involved in the present systems. These low values are correlated to the large distances between two neighboring Dy ${ }^{\mathrm{III}}$ centers (above $7 \AA$ ) and the different orientation of the magnetic axes arising from different coordination sphere natures and geometries. The $\mathrm{S}$ shape on the low-filed $M(\mathrm{H})$ curve is not visible in these cases (Figure 4) because of the small gap between the non magnetic ground state and the first excited states.

The addition of intramolecular dipolar interactions increases the description of the magnetic behavior in the low temperature range of the $\chi_{\mathrm{M}} T$ product but is not sufficient to fully picture the mechanisms involved in these complexes. Therefore, exchange interactions are considered in the computational procedure. To avoid overparametrization and due to the symmetry of the system and the large distances between the magnetic centers, a single value of the exchange constant $\left(J^{\mathrm{ex}}\right)$ is applied for all neighboring Dy-Dy pairs. The exchange term was then fitted to reproduce at the best the experimental dc magnetic data (Figure 3 ) and the values found are $-1.3 \mathrm{~cm}^{-1}$ and $-0.5 \mathrm{~cm}^{-1}$ (Lines model) for 1Dy and 2Dy, respectively. Due to the complexity of such systems, these data only give a qualitative picture of the magnetic interactions involved in these hexanuclear complexes by highlighting the presence of intramolecular antiferromagnetic dipolar and exchange contributions.

\section{CONCLUSION}

To summarize, four aesthetically fascinating lanthanidebased hexanuclear circular helicates were isolated by applying a flexible glutarohydrazode derived bis-tridentate ligand $\left(\mathrm{H}_{2} \mathrm{~L}\right)$. The X-ray structure analysis revealed that these complexes share a similar circular helicate structural topology with a wheel-shaped hexametallic core. Magnetic studies showed dominant antiferromagnetic interactions in gadolinium analogues. Moreover, 1Gd and 2Gd display significant cryogenic MCEs, with $-\Delta S_{\mathrm{m}}=14.34$ and $15.33 \mathrm{~J} \mathrm{~kg}^{-1} \mathrm{~K}^{-1}$ for 1Gd and 2Gd, respectively, at $7 \mathrm{~T}$ and $2 \mathrm{~K}$, whereas complexes 1Dy and 2Dy exhibit slow magnetic relaxation of the magnetization with rare toroidal magnetic moments. $A b$ initio calculations shed light on the origin of such magnetic behaviors arising from both the low and distorted coordination geometries of Dy ${ }^{\mathrm{III}}$ ions leading to highly anisotropic magnetic centers and the presence of antiferromagnetic intramolecular interactions stabilizing a non-magnetic ground state. This work offers new strategies for synthesizing polynuclear lanthanide-based SMMs with toroidal magnetic moments in the future.

\section{ASSOCIATED CONTENT}

\section{Supporting Information.}

Experimental procedures, additional magnetic properties measurements, TG data analysis and computational details. This material is available free of charge via the Internet at http://pubs.acs.org.

\section{AUTHOR INFORMATION}

\section{Corresponding Authors}

*E-mail: boris.leguennic@univ-rennes1.fr; tang@ciac.ac.cn

Notes

The authors declare no competing financial interest.

\section{ACKNOWLEDGMENT}

We thank the National Natural Science Foundation of China (Grants 21525103, and 21871247) for financial support. J. T. gratefully acknowledges support of the Royal Society-Newton Advanced Fellowship (NA160075). V.M. is thankful to ERC (project no. 725184) for funding. V. M. and B. L. G. thanks the French GENCI/IDRIS-CINES centers for high-performance computing resources.

\section{DEDICATION}

This paper is dedicated to Professor Annie Powell on the occasion of her 60th birthday.

\section{REFERENCES}

(1) (a) Yang, Y.-D.; Fan, C.-C.; Rambo, B. M.; Gong, H.-Y.; Xu, L.-J.; Xiang, J.-F.; Sessler, J. L. Multicomponent Self-Assembled MetalOrganic [3]Rotaxanes. J. Am. Chem. Soc. 2015, 137, 12966-12976; (b) Joosten, A.; Trolez, Y.; Collin, J.-P.; Heitz, V.; Sauvage, J.-P. Copper(I)Assembled [3]Rotaxane Whose Two Rings Act as Flapping Wings. J. Am. Chem. Soc. 2012, 134, 1802-1809; (c) Leigh, D. A.; Marcos, V.; Nalbantoglu, T.; Vitorica-Yrezabal, I. J.; Yasar, F. T.; Zhu, X. PyridylAcyl Hydrazone Rotaxanes and Molecular Shuttles. J. Am. Chem. Soc. 2017, 139, 7104-7109; (d) Hayashi, R.; Mutoh, Y.; Kasama, T.; Saito, S. Synthesis of [3]Rotaxanes by the Combination of Copper-Mediated Coupling Reaction and Metal-Template Approach. J. Org. Chem. 2015, 80, 7536-7546; (e) Kraus, T.; Buděšínský, M.; Cvačka, J.; Sauvage, J.-P. Copper(I)-Directed Formation of a Cyclic Pseudorotaxane Tetramer and Its Trimeric Homologue. Angew. Chem. Int. Ed. 2006, 45, 258-261.

(2) (a) Wood, C. S.; Ronson, T. K.; Belenguer, A. M.; Holstein, J. J.; Nitschke, J. R. Two-stage directed self-assembly of a cyclic [3]catenane. Nat. Chem, 2015, 7, 354; (b) Samanta, D.; Mukherjee, P. S. SunlightInduced Covalent Marriage of Two Triply Interlocked $\mathrm{Pd}_{6}$ Cages and Their Facile Thermal Separation. J. Am. Chem. Soc. 2014, 136, 1700617009; (c) Zhu, R.; Lübben, J.; Dittrich, B.; Clever, G. H. Stepwise Halide-Triggered Double and Triple Catenation of Self-Assembled 
Coordination Cages. Angew. Chem. Int. Ed. 2015, 54, 2796-2800; (d) Dietrich-Buchecker, C. O.; Sauvage, J. P.; Kern, J. M. Templated synthesis of interlocked macrocyclic ligands: The catenands. J. Am. Chem. Soc. 1984, 106, 3043-3045; (e) Fujita, M.; Ibukuro, F.; Hagihara, H.; Ogura, K. Quantitative self-assembly of a [2]catenane from two preformed molecular rings. Nature 1994, 367, 720 .

(3) (a) Danon, J. J.; Krüger, A.; Leigh, D. A.; Lemonnier, J.-F.; Stephens, A. J.; Vitorica-Yrezabal, I. J.; Woltering, S. L. Braiding a molecular knot with eight crossings. Science 2017, 355, 159-162; (b) Ayme, J.-F.; Beves, J. E.; Leigh, D. A.; McBurney, R. T.; Rissanen, K.; Schultz, D. A synthetic molecular pentafoil knot. Nat. Chem, 2011, 4, 15; (c) Ayme, J.F.; Beves, J. E.; Campbell, C. J.; Leigh, D. A. Template synthesis of molecular knots. Chem. Soc. Rev. 2013, 42, 1700-1712.

(4) (a) Beves, J. E.; Danon, J. J.; Leigh, D. A.; Lemonnier, J.-F.; VitoricaYrezabal, I. J. A Solomon Link through an Interwoven Molecular Grid. Angew. Chem. Int. Ed. 2015, 54, 7555-7559; (b) Chichak, K. S.; Cantrill, S. J.; Pease, A. R.; Chiu, S.-H.; Cave, G. W. V.; Atwood, J. L.; Stoddart, J. F. Molecular Borromean Rings. Science 2004, 304, 1308-1312.

(5) (a) Wu, J.; Zhao, L.; Zhang, L.; Li, X.-L.; Guo, M.; Powell, A. K.; Tang, J. Macroscopic Hexagonal Tubes of $3 \mathrm{~d}-4 \mathrm{f}$ Metallocycles. Angew. Chem. Int. Ed. 2016, 55, 15574-15578; (b) Stang, P. J.; Cao, D. H. Transition metal based cationic molecular boxes. Self-assembly of macrocyclic platinum (II) and palladium (II) tetranuclear complexes. $J$. Am. Chem. Soc. 1994, 116, 4981-4982; (c) Chifotides, H. T.; Giles, I. D.; Dunbar, K. R. Supramolecular Architectures with $\pi$-Acidic 3,6-Bis(2pyridyl)-1,2,4,5-tetrazine Cavities: Role of Anion- $\pi$ Interactions in the Remarkable Stability of Fe(II) Metallacycles in Solution. J. Am. Chem. Soc. 2013, 135, 3039-3055; (d) Alexandropoulos, D. I.; Dolinar, B. S.; Vignesh, K. R.; Dunbar, K. R. Putting a New Spin on Supramolecular Metallacycles: $\mathrm{Co}_{3}$ Triangle and $\mathrm{Co}_{4}$ Square Bearing Tetrazine-Based Radicals as Bridges. J. Am. Chem. Soc. 2017, 139, 11040-11043; (e) Sautter, A.; Schmid, D. G.; Jung, G.; Würthner, F. A Triangle-Square Equilibrium of Metallosupramolecular Assemblies Based on $\mathrm{Pd}(\mathrm{II})$ and Pt(II) Corners and Diazadibenzoperylene Bridging Ligands. J. Am. Chem. Soc. 2001, 123, 5424-5430.

(6) (a) Sun, Q.-F.; Iwasa, J.; Ogawa, D.; Ishido, Y.; Sato, S.; Ozeki, T.; Sei, Y.; Yamaguchi, K.; Fujita, M. Self-Assembled $\mathrm{M}_{24} \mathrm{~L}_{48}$ Polyhedra and Their Sharp Structural Switch upon Subtle Ligand Variation. Science 2010, 328, 1144-1147; (b) Han, M.; Luo, Y.; Damaschke, B.; Gómez, L.; Ribas, X.; Jose, A.; Peretzki, P.; Seibt, M.; Clever, G. H. Light-Controlled Interconversion between a Self-Assembled Triangle and a Rhombicuboctahedral Sphere. Angew. Chem. Int. Ed. 2016, 55, 445-449; (c) Olenyuk, B.; Whiteford, J. A.; Fechtenkötter, A.; Stang, P. J. Selfassembly of nanoscale cuboctahedra by coordination chemistry. Nature 1999, 398, 796; (d) Olenyuk, B.; Levin, M. D.; Whiteford, J. A.; Shield, J. E.; Stang, P. J. Self-assembly of nanoscopic dodecahedra from 50 predesigned components. J. Am. Chem. Soc. 1999, 121, 10434-10435.

(7) (a) Aroussi, B. E.; Zebret, S.; Besnard, C.; Perrottet, P.; Hamacek, J. Rational Design of a Ternary Supramolecular System: Self-Assembly of Pentanuclear Lanthanide Helicates. J. Am. Chem. Soc. 2011, 133, 10764 10767; (b) Hasenknopf, B.; Lehn, J.-M.; Kneisel, B. O.; Baum, G.; Fenske, D. Self-Assembly of a Circular Double Helicate. Angew. Chem. Int. Ed. 1996, 35, 1838-1840; (c) Li, X.-Z.; Zhou, L.-P.; Yan, L.-L.; Yuan, D.-Q.; Lin, C.-S.; Sun, Q.-F. Evolution of Luminescent Supramolecular Lanthanide M2nL3n Complexes from Helicates and Tetrahedra to Cubes. J. Am. Chem. Soc. 2017, 139, 8237-8244; (d) Ayme, J.-F.; Beves, J. E.; Leigh, D. A.; McBurney, R. T.; Rissanen, K.; Schultz, D. Pentameric Circular Iron(II) Double Helicates and a Molecular Pentafoil Knot. J. Am. Chem. Soc. 2012, 134, 9488-9497; (e) Bretonnière, Y.; Mazzanti, M.; Pécaut, J.; Olmstead, M. M. Cation-Controlled Self-Assembly of a Hexameric Europium Wheel. J. Am. Chem. Soc. 2002, 124, 9012-9013.

(8) (a) Wu, J.; Zhao, L.; Zhang, L.; Li, X.-L.; Guo, M.; Tang, J. Metallosupramolecular Coordination Complexes: The Design of Heterometallic 3d-4f Gridlike Structures. Inorg. Chem. 2016, 55, 55145519; (b) Bassani, D. M.; Lehn, J.-M.; Fromm, K.; Fenske, D. Toposelective and Chiroselective Self-Assembly of [2×2] Grid-Type Inorganic Arrays Containing Different Octahedral Metallic Centers Angew. Chem. Int. Ed. 1998, 37, 2364-2367; (c) Barboiu, M.; Vaughan, G.; Graff, R.; Lehn, J.-M. Self-Assembly, Structure, and Dynamic Interconversion of Metallosupramolecular Architectures Generated by $\mathrm{Pb}$ (II) Binding-Induced Unfolding of a Helical Ligand. J. Am. Chem. Soc. 2003, 125, 10257-10265; (d) Wu, J.; Zhao, L.; Guo, M.; Tang, J. Constructing supramolecular grids: from $4 \mathrm{f}$ square to $3 \mathrm{~d}-4 \mathrm{f}$ grid. Chem. Commun. 2015, 51, 17317-17320.
(9) (a) Xuan, W.; Zhang, M.; Liu, Y.; Chen, Z.; Cui, Y. A Chiral Quadruple-Stranded Helicate Cage for Enantioselective Recognition and Separation. J. Am. Chem. Soc. 2012, 134, 6904-6907; (b) Matthews, C. J.; Onions, S. T.; Morata, G.; Davis, L. J.; Heath, S. L.; Price, D. J. A SelfAssembled Tetracopper Triple-Stranded Helicate: Towards the Controlled Synthesis of Finite One-Dimensional Magnetic Chains. Angew. Chem. Int. Ed. 2003, 42, 3166-3169; (c) Kaminker, R.; de Hatten, X.; Lahav, M.; Lupo, F.; Gulino, A.; Evmenenko, G.; Dutta, P.; Browne, C.; Nitschke, J. R.; van der Boom, M. E. Assembly of Surface-Confined Homochiral Helicates: Chiral Discrimination of DOPA and Unidirectional Charge Transfer. J. Am. Chem. Soc. 2013, 135, 17052-17059; (d) Baudron, S. A.; Ruffin, H.; Hosseini, M. W. On Zn(II) 2,2'-bisdipyrrin circular helicates. Chem. Commun. 2015, 51, 5906-5909.

(10) (a) Bocquet, B.; Bernardinelli, G.; Ouali, N.; Floquet, S.; Renaud, F.; Hopfgartner, G.; Piguet, C. The first self-assembled trimetallic lanthanide helicate: different coordination sites in symmetrical molecular architectures. Chem. Commun. 2002, 930-931; (b) Li, X.-L.; Wu, J.; Zhao, L.; Shi, W.; Cheng, P.; Tang, J. End-to-end azido-pinned interlocking lanthanide squares. Chem. Commun. 2017, 53, 3026-3029; (c) Ronson, T. K.; Adams, H.; Harding, L. P.; Pope, S. J. A.; Sykes, D.; Faulkner, S.; Ward, M. D. Polynuclear lanthanide complexes of a series of bridging ligands containing two tridentate N,N',O-donor units: structures and luminescence properties. Dalton Trans. 2007, 1006-1022; (d) Chen, W.; Tang, X.; Dou, W.; Wang, B.; Guo, L.; Ju, Z.; Liu, W. The Construction of Homochiral Lanthanide Quadruple-Stranded Helicates with Multiresponsive Sensing Properties toward Fluoride Anions. Chem. Eur. J. 2017, 23, 9804-9811; (e) Bünzli, J.-C. G.; Piguet, C. LanthanideContaining Molecular and Supramolecular Polymetallic Functional Assemblies. Chem. Rev. 2002, 102, 1897-1928; (f) Wang, B.; Zang, Z.; Wang, H.; Dou, W.; Tang, X.; Liu, W.; Shao, Y.; Ma, J.; Li, Y.; Zhou, J. Multiple Lanthanide Helicate Clusters and the Effects of Anions on Their Configuration. Angew. Chem. Int. Ed. 2013, 52, 3756-3759.

(11) (a) Terazzi, E.; Zaïm, A.; Bocquet, B.; Varin, J.; Guénée, L.; Dutronc, T.; Lemonnier, J.-F.; Floquet, S.; Cadot, E.; Heinrich, B.; Donnio, B.; Piguet, C. Implementing Liquid-Crystalline Properties in Single-Stranded Dinuclear Lanthanide Helicates. Eur. J. Inorg. Chem. 2013, 2013, 33233333; (b) Lemonnier, J.-F.; Guénée, L.; Bernardinelli, G.; Vigier, J.-F.; Bocquet, B.; Piguet, C. Planned Failures from the Principle of Maximum Site Occupancy in Lanthanide Helicates. Inorg. Chem. 2010, 49, 12521265.

(12) Sahoo, J.; Arunachalam, R.; Subramanian, P. S.; Suresh, E.; Valkonen, A.; Rissanen, K.; Albrecht, M. Coordinatively Unsaturated Lanthanide(III) Helicates: Luminescence Sensors for Adenosine Monophosphate in Aqueous Media. Angew. Chem. Int. Ed. 2016, 55, 9625-9629.

(13) (a) Zeckert, K.; Hamacek, J.; Senegas, J.-M.; Dalla-Favera, N.; Floquet, S.; Bernardinelli, G.; Piguet, C. Predictions, Synthetic Strategy, and Isolation of a Linear Tetrametallic Triple-Stranded Lanthanide Helicate. Angew. Chem. Int. Ed. 2005, 44, 7954-7958; (b) Li, H.; Chen, P.; Sun, W.; Zhang, L.; Yan, P. Solvent triggered structural diversity of triplestranded helicates: single molecular magnets. Dalton Trans. 2016, 45, 3175-3181; (c) Martin, N.; Bünzli, J.-C. G.; McKee, V.; Piguet, C.; Hopfgartner, G. Self-Assembled Dinuclear Lanthanide Helicates: Substantial Luminescence Enhancement upon Replacing Terminal Benzimidazole Groups by Carboxamide Binding Units. Inorg. Chem. 1998, 37, 577-589.

(14) (a) Mondal, A. K.; Jena, H. S.; Malviya, A.; Konar, S. LanthanideDirected Fabrication of Four Tetranuclear Quadruple Stranded Helicates Showing Magnetic Refrigeration and Slow Magnetic Relaxation. Inorg. Chem. 2016, 55, 5237-5244; (b) Habib, F.; Long, J.; Lin, P.-H.; Korobkov, I.; Ungur, L.; Wernsdorfer, W.; Chibotaru, L. F.; Murugesu, M. Supramolecular architectures for controlling slow magnetic relaxation in field-induced single-molecule magnets. Chem. Sci. 2012, 3, 2158-2164. (15) (a) Senegas, J.-M.; Koeller, S.; Bernardinelli, G.; Piguet, C. Isolation and characterization of the first circular single-stranded polymetallic lanthanide-containing helicate. Chem. Commun. 2005, 2235-2237; (b) Zhang, L.; Zhang, P.; Zhao, L.; Wu, J.; Guo, M.; Tang, J. Anions Influence the Relaxation Dynamics of Mono- $\mu_{3}-\mathrm{OH}-\mathrm{Capped}$ Triangular Dysprosium Aggregates. Inorg. Chem. 2015, 54, 5571-5578; (c) Lin, S.Y.; Zhao, L.; Guo, Y.-N.; Zhang, P.; Guo, Y.; Tang, J. Two New Dy Triangles with Trinuclear Circular Helicates and Their Single-Molecule Magnet Behavior. Inorg. Chem. 2012, 51, 10522-10528.

(16) (a) Sessoli, R.; Gatteschi, D.; Caneschi, A.; Novak, M. A. Magnetic bistability in a metal-ion cluster. Nature 1993, 365, 141-143; (b) Christou, 
G.; Gatteschi, D.; Hendrickson, D. N.; Sessoli, R. Single-Molecule Magnets. MRS Bull. 2000, 25, 66-71.

(17) (a) Tang, J.; Hewitt, I.; Madhu, N. T.; Chastanet, G.; Wernsdorfer, W.; Anson, C. E.; Benelli, C.; Sessoli, R.; Powell, A. K. Dysprosium Triangles Showing Single-Molecule Magnet Behavior of Thermally Excited Spin States. Angew. Chem. Int. Ed. 2006, 45, 1729-1733; (b) Lin, S.-Y.; Wernsdorfer, W.; Ungur, L.; Powell, A. K.; Guo, Y.-N.; Tang, J.; Zhao, L.; Chibotaru, L. F.; Zhang, H.-J. Coupling $\mathrm{Dy}_{3}$ Triangles to Maximize the Toroidal Moment. Angew. Chem. Int. Ed. 2012, 51, $12767-$ 12771; (c) Chibotaru, L. F.; Ungur, L.; Soncini, A. The Origin of Nonmagnetic Kramers Doublets in the Ground State of Dysprosium Triangles: Evidence for a Toroidal Magnetic Moment. Angew. Chem. Int. Ed. 2008, 47, 4126-4129; (d) Ungur, L.; Lin, S.-Y.; Tang, J.; Chibotaru, L. F. Single-molecule toroics in Ising-type lanthanide molecular clusters. Chem. Soc. Rev. 2014, 43, 6894-6905; (e) Biswas, S.; Das, S.; Gupta, T.; Singh, S. K.; Pissas, M.; Rajaraman, G.; Chandrasekhar, V. Observation of Slow Relaxation and Single-Molecule Toroidal Behavior in a Family of Butterfly-Shaped $\mathrm{Ln}_{4}$ Complexes. Chem. Eur. J. 2016, 22, 18532-18550; (f) Langley, S. K.; Vignesh, K. R.; Moubaraki, B.; Rajaraman, G.; Murray, K. S. Oblate versus Prolate Electron Density of Lanthanide Ions: A Design Criterion for Engineering Toroidal Moments? A Case Study on $\left\{\mathrm{Ln}_{6}^{\mathrm{III}}{ }_{6}\right\}(\mathrm{Ln}=\mathrm{Tb}$, Dy, Ho and Er) Wheels. Chem. Eur. J. 2019, 25, 41564165.

(18) Phan, M.-H.; Yu, S.-C. Review of the magnetocaloric effect in manganite materials. J. Magn. Magn. Mater. 2007, 308, 325-340.

(19) (a) Guo, Y.-N.; Xu, G.-F.; Wernsdorfer, W.; Ungur, L.; Guo, Y.; Tang, J.; Zhang, H.-J.; Chibotaru, L. F.; Powell, A. K. Strong Axiality and Ising Exchange Interaction Suppress Zero-Field Tunneling of Magnetization of an Asymmetric $\mathrm{Dy}_{2}$ Single-Molecule Magnet. J. Am. Chem. Soc. 2011, 133, 11948-11951; (b) Chilton, N. F.; Collison, D.; McInnes, E. J. L.; Winpenny, R. E. P.; Soncini, A. An electrostatic mode for the determination of magnetic anisotropy in dysprosium complexes Nat. Commun. 2013, 4, 2551; (c) Ungur, L.; Langley, S. K.; Hooper, T. N.; Moubaraki, B.; Brechin, E. K.; Murray, K. S.; Chibotaru, L. F. Net Toroidal Magnetic Moment in the Ground State of a $\left\{\mathrm{Dy}_{6}\right\}-$ Triethanolamine Ring. J. Am. Chem. Soc. 2012, 134, 18554-18557; (d) Gusev, A.; Herchel, R.; Nemec, I.; Shul'gin, V.; Eremenko, I. L.; Lyssenko, K.; Linert, W.; Trávníček, Z. Tetranuclear Lanthanide Complexes Containing a Hydrazone-type Ligand. Dysprosium [2 $\times 2$ ] Gridlike Single-Molecule Magnet and Toroic. Inorg. Chem. 2016, 55, $12470-12476$

(20) (a) Zhang, P.; Zhang, L.; Wang, C.; Xue, S.; Lin, S.-Y.; Tang, J. Equatorially Coordinated Lanthanide Single Ion Magnets. J. Am. Chem. Soc. 2014, 136, 4484-4487; (b) Jiang, S.-D.; Wang, B.-W.; Sun, H.-L.; Wang, Z.-M.; Gao, S. An Organometallic Single-Ion Magnet. J. Am. Chem. Soc. 2011, 133, 4730-4733; (c) Ishikawa, N.; Sugita, M.; Ishikawa, T.; Koshihara, S.-y.; Kaizu, Y. Lanthanide Double-Decker Complexes Functioning as Magnets at the Single-Molecular Level. J. Am. Chem. Soc. 2003, 125, 8694-8695.

(21) (a) Zheng, Y.-Z.; Zhou, G.-J.; Zheng, Z.; Winpenny, R. E. P. Molecule-based magnetic coolers. Chem. Soc. Rev. 2014, 43, 1462-1475; (b) Liu, J.-L.; Chen, Y.-C.; Guo, F.-S.; Tong, M.-L. Recent advances in the design of magnetic molecules for use as cryogenic magnetic coolants. Coord. Chem. Rev. 2014, 281, 26-49.

(22) Pyykkö, P. Magically magnetic gadolinium. Nat. Chem, 2015, 7, 680680.

(23) Pugh, T.; Chilton, N. F.; Layfield, R. A. A Low-Symmetry Dysprosium Metallocene Single-Molecule Magnet with a High Anisotropy Barrier. Angew. Chem. Int. Ed. 2016, 55, 11082-11085.

(24) Blagg, R. J.; Tuna, F.; McInnes, E. J. L.; Winpenny, R. E. P. Pentametallic lanthanide-alkoxide square-based pyramids: high energy barrier for thermal relaxation in a holmium single molecule magnet Chem. Commun. 2011, 47, 10587-10589.

(25) Blagg, R. J.; Ungur, L.; Tuna, F.; Speak, J.; Comar, P.; Collison, D. Wernsdorfer, W.; McInnes, E. J. L.; Chibotaru, L. F.; Winpenny, R. E. P. Magnetic relaxation pathways in lanthanide single-molecule magnets. Nat Chem 2013, 5, 673-678

(26) Fernandez Garcia, G.; Guettas, D.; Montigaud, V.; Larini, P.; Sessoli, R.; Totti, F.; Cador, O.; Pilet, G.; Le Guennic, B. A Dy ${ }_{4}$ Cubane: A New
Member in the Single-Molecule Toroics Family. Angew. Chem. Int. Ed. 2018, 57, 17089-17093.

(27) Dong, J.; Cui, P.; Shi, P.-F.; Cheng, P.; Zhao, B. Ultrastrong AlkaliResisting Lanthanide-Zeolites Assembled by $\left[\mathrm{Ln}_{60}\right]$ Nanocages. $\mathrm{J}$. Am. Chem. Soc. 2015, 137, 15988-15991.

(28) Baniodeh, A.; Magnani, N.; Brase, S.; Anson, C. E.; Powell, A. K. Ligand field variations: tuning the toroidal moment of Dy $\mathrm{y}_{6}$ rings. Dalton Trans. 2015, 44, 6343-6347.

(29) Li, X.-L.; Wu, J.; Tang, J.; Le Guennic, B.; Shi, W.; Cheng, P. A planar triangular $\mathrm{Dy}_{3}+\mathrm{Dy}_{3}$ single-molecule magnet with a toroidal magnetic moment. Chem. Commun. 2016, 52, 9570-9573.

(30) Casanova, D.; Llunell, M.; Alemany, P.; Alvarez, S. The Rich Stereochemistry of Eight-Vertex Polyhedra: A Continuous Shape Measures Study. Chem. Eur. J. 2005, 11, 1479-1494.

(31) Bing, T. Y.; Kawai, T.; Yuasa, J. Ligand-to-Ligand Interactions That Direct Formation of $D_{2}$-Symmetrical Alternating Circular Helicate. $J$. Am. Chem. Soc. 2018, 140, 3683-3689.

(32) Malviya, A.; Jena, H. S.; Mondal, A. K.; Konar, S. Europium-Based Dinuclear Triple-Stranded Helicate vs. Tetranuclear Quadruple-Stranded Helicate: Effect of Stoichiometric Ratio on the Supramolecular SelfAssembly. Eur. J. Inorg. Chem. 2015, 2015, 2901-2907.

(33) Kahn, O. Molecular magnetism. VCH: New York, 1993.

(34) Zhang, L.; Zhao, L.; Zhang, P.; Wang, C.; Yuan, S.-W.; Tang, J. Nanoscale $\left\{\mathrm{Ln}_{24}^{\mathrm{III}} \mathrm{Zn}_{6}{ }_{6}^{\mathrm{II}}\right\} \quad$ Triangular Metalloring with Magnetic Refrigerant, Slow Magnetic Relaxation, and Fluorescent Properties. Inorg. Chem. 2015, 54, 11535-11541.

(35) Chilton, N. F.; Anderson, R. P.; Turner, L. D.; Soncini, A.; Murray, K. S. PHI: A powerful new program for the analysis of anisotropic monomeric and exchange-coupled polynuclear d- and f-block complexes. J. Comput. Chem. 2013, 34, 1164-1175.

(36) Lin, S.-Y.; Li, X.-L.; Ke, H.; Xu, Z. A series of tetranuclear lanthanide compounds constructed by in situ polydentate ligands: synthesis, structure, and SMM behaviour of the $\mathrm{Dy}_{4}$ compound. CrystEngComm 2015, 17, 9167-9174.

(37) (a) Ke, H.; Xu, G.-F.; Zhao, L.; Tang, J.; Zhang, X.-Y.; Zhang, H.-J. A $\mathrm{Dy}_{10}$ Cluster Incorporates Two Sets of Vertex-Sharing Dy $\mathrm{y}_{3}$ Triangles. Chem. Eur. J. 2009, 15, 10335-10338; (b) Langley, S. K.; Moubaraki, B.; Forsyth, C. M.; Gass, I. A.; Murray, K. S. Structure and magnetism of new lanthanide 6-wheel compounds utilizing triethanolamine as a stabilizing ligand. Dalton Trans. 2010, 39, 1705-1708

(38) (a) Alexandropoulos, D. I.; Cunha-Silva, L.; Pham, L.; Bekiari, V.; Christou, G.; Stamatatos, T. C. Tetranuclear Lanthanide(III) Complexes with a Zigzag Topology from the Use of Pyridine-2,6-dimethanol: Synthetic, Structural, Spectroscopic, Magnetic and Photoluminescence Studies. Inorg. Chem. 2014, 53, 3220-3229; (b) Zhang, L.; Zhang, Y.-Q.; Zhang, P.; Zhao, L.; Guo, M.; Tang, J. Single-Molecule Magnet Behavior Enhanced by Synergic Effect of Single-Ion Anisotropy and Magnetic Interactions. Inorg. Chem. 2017, 56, 7882-7889; (c) Mukherjee, S.; Lu, J.; Velmurugan, G.; Singh, S.; Rajaraman, G.; Tang, J.; Ghosh, S. K. Influence of Tuned Linker Functionality on Modulation of Magnetic Properties and Relaxation Dynamics in a Family of Six Isotypic $\mathrm{Ln}_{2}(\mathrm{Ln}=$ Dy and Gd) Complexes. Inorg. Chem. 2016, 55, 11283-11298.

(39) (a) Ilmi, R.; Iftikhar, K. Pyrazine bridged $\mathrm{Ln}_{2}$ (La, Nd, Eu and Tb) complexes containing fluorinated $\beta$-diketone. Inorg. Chem. Commun. 2012, 20, 7-12; (b) Debye, P. Einige Bemerkungen zur Magnetisierung bei tiefer Temperatur. Ann. Phys. 1926, 386, 1154-1160

(40) Wu, J.; Li, X.-L.; Zhao, L.; Guo, M.; Tang, J. Enhancement of Magnetocaloric Effect through Fixation of Carbon Dioxide: Molecular Assembly from $\mathrm{Ln}_{4}$ to $\mathrm{Ln}_{4}$ Cluster Pairs. Inorg. Chem. 2017, 56, 4104 4111.

(41) Bartolomé, J.; Filoti, G.; Kuncser, V.; Schinteie, G.; Mereacre, V.; Anson, C. E.; Powell, A. K.; Prodius, D.; Turta, C. Magnetostructural correlations in the tetranuclear series of $\left\{\mathrm{Fe}_{3} \mathrm{LnO}_{2}\right\}$ butterfly core clusters: Magnetic and Mössbauer spectroscopic study. Phys. Rev. B 2009, 80, 014430 . 


\section{SYNOPSIS TOC}

Hexanuclear circular helicates $\operatorname{Ln}_{6}(\mathrm{Ln}=$ Dy and $\mathrm{Gd})$ exhibit single-molecule-magnet behavior with toroidal arrangement of the magnetic moments and magnetocaloric effects, depending on the metal ion.

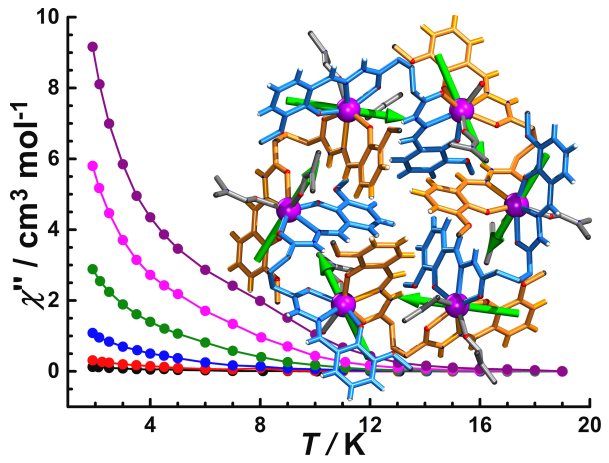

